\title{
A Fair Deal for mental health includes local rehabilitation services ${ }^{\dagger}$
}

\author{
Helen Killaspy, ${ }^{1}$ Richard Meier $^{2}$
}

The Psychiatrist (2010), 34, 265-267, doi: 10.1192/pb.bp.109.028530

${ }^{1}$ Royal Free and University College London Medical School, and Camden and Islington NHS Foundation Trust, London; ${ }^{2}$ Royal College of Psychiatrists Correspondence to Helen Killaspy (h.killaspy@medsch.ucl.ac.uk)
Summary Lack of policy for mental health rehabilitation services has led to disinvestment and expansion of out-of-area placements in in-patient, nursing and residential care settings in the independent sector. Although a minority provide very specialist services that cannot be provided locally, and many provide good-quality care, there are significant concerns about the lack of rehabilitation focus in some of those services, poor links with local care managers and the social dislocation caused by being placed many miles from home. Additionally, out-of-area placements cost more than local rehabilitation services. There is, therefore, a compelling case for all individuals with complex mental health problems to have access to local rehabilitation services in order to expedite their recovery and social inclusion. The Faculty of Rehabilitation and Social Psychiatry of the Royal College of Psychiatrists has recently published a service template to guide commissioners and service providers in the UK in the kinds of rehabilitation services they need to provide locally.

Declaration of interest H.K. is the Chair of the Royal College of Psychiatrists' Faculty of Rehabilitation and Social Psychiatry.
Until recently, the majority of mental health trusts in England provided in-patient rehabilitation services, ${ }^{1}$ but in the past 3 years or so this situation has changed dramatically. Provision has become increasingly patchy, with uncoordinated local disinvestment and complete closure of some services. At the same time there has been a major expansion of in-patient, residential and nursing care in the independent sector. ${ }^{2,3}$ This disinvestment in local National Health Service (NHS) rehabilitation services has not come about through government policy. There is no policy. It is the view of the Faculty of Rehabilitation and Social Psychiatry of the Royal College of Psychiatrists that it has come about as a direct result of the lack of acknowledgement of the need for rehabilitation services in the Department of Health's National Service Framework for Mental Health. ${ }^{4}$ The subsequent NHS $\operatorname{plan}^{5}$ focused on implementation of specialist crisis resolution, early intervention and assertive outreach teams to meet government targets. Although the investment in community-based services that the National Service Framework brought was very welcome, absence of policy and guidance on rehabilitation services appears to have resulted in the mistaken view that there would no longer be a need for rehabilitation services, as though the people who use them would automatically be absorbed into the new specialist services. In this process, a third of community rehabilitation teams were simply rebadged as assertive outreach teams (Wright, personal communication, 2009). One of the main objectives for the new specialist teams was to reduce

†See special article, pp. 290-291, this issue reliance on in-patient services, ${ }^{6}$ but time has shown that a small proportion of service users continue to require lengthy hospital admission even when they are also in receipt of treatment and care from the new teams. ${ }^{7,8}$

At any time, about $1 \%$ of people with severe and enduring mental health problems such as schizophrenia require intensive in-patient rehabilitation. ${ }^{2,9}$ Most are referred when it has become clear that following the National Institute for Health and Clinical Excellence's treatment algorithm has not enabled them to recover well enough to leave hospital. ${ }^{2}$ Delayed recovery may be caused by various factors such as treatment resistance, cognitive impairment, severe negative symptoms, substance misuse, comorbidities and challenging behaviour., ${ }^{2,9-12}$ In other words, this patient group has highly complex mental health needs and is considered one of the most socially excluded in society. ${ }^{13}$ There is, however, encouraging evidence that with appropriate treatment in a suitable specialist rehabilitation setting even those individuals whose difficulties are considered to be the most challenging can progress over time to successful and stable community living. ${ }^{14,15}$

\section{Out-of-area placements}

The recent disinvestment in NHS rehabilitation services has resulted in a rapid and uncontrolled rise in independent sector provision of in-patient, residential and nursing care, so-called out-of-area treatments. Although many provide good-quality care and a minority of providers focus on very specialist care that cannot be provided locally, criticisms 
have been made about the lack of rehabilitation focus in some, with over-supportive care plans, inadequate implementation of the care programme approach and overrestrictive and institutionalised practices that deskill individuals rather than preparing them for more independent living. ${ }^{16}$ The distance from home associated with many out-of-area treatments results in social dislocation of service users from their family, friends and local community. Even where the distance from home is not so great, being placed outside the local area leads to a lack of continuity of care coordination and care management, which results in longer stays than are necessary. ${ }^{17}$ In addition, mental health commissioners have been found to have inaccurate data about the individuals they fund in these placements and inadequate systems for reviewing the need for their ongoing care. ${ }^{18}$

\section{Cost of out-of-area placements}

Out-of-area treatments represent a huge financial burden to the public sector and they are more expensive than local provision. In 2004-2005, they cost the NHS $£ 222$ million, an increase of $63 \%$ over the previous year. ${ }^{19} \mathrm{~A}$ request for information about out-of-area treatment placements and expenditure to all primary care trusts and local authorities in England (using the Freedom of Information Act) made by the Faculty of Rehabilitation and Social Psychiatry with assistance from the College's Policy Unit, achieved a 77\% response and found that $21 \%$ of residential and nursing care placements in England were in out-of-area treatments. This proportion seems surprisingly high considering that only a very small proportion of individuals require very specialist care that can only be provided in specialist out-of-area settings. In addition, this survey found that on average outof-area placements cost $64 \%$ more than local placements (primary care trust-funded out-of-area treatments cost $100 \%$ more than local primary care trust-funded placements, whereas local authority-funded out-of-area treatments cost $40 \%$ more than local authority-funded local placements). The average annual cost of a local placement was $£ 21 \mathrm{k}$ and that of an out-of-area treatment $£ 35 \mathrm{k}$. The total combined NHS and local authority spend on out-ofarea treatments in 2008-2009 was around £330 million. It therefore appears that the lack of policy for rehabilitation services has created a wasteful, uncoordinated, poorly monitored 'virtual asylum, ${ }^{20,21}$ which is unlikely to promote recovery and social inclusion for service users.

\section{Repatriating service users locally}

Some rehabilitation services and primary care trusts (e.g. Berkshire, Wigan, and Bromley, Islington and Hackney in London) have set up systems to review and 'repatriate' people placed in out-of-area treatments back to their area of origin, usually to less restrictive and more independent settings such as supported tenancies. In some areas, the associated financial flows have been reinvested into rehabilitation services and high-quality supported housing initiatives, developed through successful collaborations between third-sector providers, commissioners and local mental health services. ${ }^{17}$ These whole-system approaches are willing to 'invest to save' by employing one or two staff to carry out detailed reviews of all individuals placed out of area in the first instance and successfully reinvesting the additional costs of out-of-area treatments into the local mental health economy. The success of this type of approach is dependent on good, coherent commissioning in partnership with local rehabilitation services and providers of residential care and supported accommodation. Reinvestment builds not only local resources to facilitate service users in achieving greater autonomy and independence, but also local confidence in caring for others with similar needs. It also reduces the future need for out-of-area treatments.

In Islington, about $40 \%$ of individuals who were placed out of area and reviewed as clinically appropriate to be repatriated to a local facility subsequently moved. ${ }^{17}$ An estimate of the financial flows that could be reinvested into local rehabilitation services and supported accommodation by repatriating $40 \%$ of the individuals currently placed in out-of-area treatments nationally is well over $£ 100$ million. This figure includes the costs of local placements that offer a similar level of support to the out-of-area placement. However, in Islington the financial advantages were further enhanced because all those who were repatriated moved to more independent placements. This is further evidence that many people placed in out-of-area treatments are oversupported and not actively facilitated to regain independent living skills.

In his ministerial foreword to the government's latest policy for mental health services (New Horizons), the Secretary of State for Health, Andy Burnham, stresses that a stronger commitment across businesses, public services and the third sector will be required to support people at risk, but that 'the potential gains we can make here are massive - huge savings to the public finances, enormous scope to improve lives and help people make a full contribution in work and in the community' (p.6). ${ }^{22}$ It would be difficult to argue with this sentiment at any time but the need to deliver cost-effective services is even more important during an economic recession. The Faculty of Rehabilitation and Social Psychiatry supports the overarching aims of New Horizons - to reduce the stigma experienced by people with mental health problems, to build a cross-government multi-agency alliance to tackle the precipitating and perpetuating social factors associated with mental illness, to improve social inclusion for people with mental health problems and to promote the delivery of personalised care based on individual needs and wishes. These themes resonate well with those working within rehabilitation psychiatry and embody the ethos of a recovery-oriented approach. ${ }^{23}$ However, the gross oversight in New Horizons is the lack of acknowledgement of the role of rehabilitation services in delivering this agenda. This omission has potentially very negative consequences for service users with complex mental health needs.

There is currently an 'out of sight, out of mind' approach to out-of-area placements that leads to a stigmatising marginalisation of those with the most severe mental health problems. Use of this virtual asylum of dispersed resources and discontinuous care pathways risks repeating the historic disenfranchisement of people with mental health disability that deinstitutionalisation aimed to 
address. It does not promote social inclusion and is not an efficient use of public resources. It is hard to find another example in the NHS where a patient has to leave their home town and move to a facility many miles away for a number of years to access a standard treatment environment. Rehabilitation services can provide local services for local people that deliver personalised care, which is tailored to the individual's needs and promotes their recovery and social inclusion. They potentially also provide a teaching, training and support resource for the broader care community in working with those with more complex mental health problems.

\section{Fair Deal for rehabilitation psychiatry}

The Royal College of Psychiatrists' Fair Deal initiative (www.rcpsych.ac.uk/campaigns/fairdeal.aspx) has officially endorsed the case for national policy to support continued investment in mental health rehabilitation services. One of the key aims of Fair Deal is to formulate a clear UK rehabilitation policy. Rehabilitation services operate as a whole system that includes close liaison between local authorities, primary care trusts, secondary mental health services and third-sector providers of community-based care (including supported accommodation, supported employment and other vocational rehabilitation services). We believe that there is a compelling case for all individuals with complex mental health problems to have access to local rehabilitation services across the whole of the UK and we have therefore compiled a rehabilitation service template to guide commissioners and service providers in the kinds of services they need to provide. ${ }^{24}$ This template was officially launched at the Faculty's annual conference in Leeds in November 2009.

Along with our colleagues working in other areas of secondary mental health services, we are particularly concerned that the government policy focus on mental health promotion as laid out in New Horizons may lead to further disinvestment in services for those with the most serious and complex mental health problems. It is difficult to see how such a focus can be delivered without disinvestment in established mental health services and systems. During a consultation event earlier this year, the National Director for Mental Health gave reassurances to the Royal College of Psychiatrists that this would not happen, and we would like to see a clear statement in New Horizons guiding commissioners and service providers to continue to invest in cost-effective, local secondary mental health services including rehabilitation services. Otherwise the aims of the government's policy - to promote social inclusion and recovery for people with complex mental health problems - will remain rhetoric rather than becoming reality.

\section{About the authors}

Helen Killaspy is Chair of the Faculty of Rehabilitation and Social Psychiatry at the Royal College of Psychiatrists, and Senior Lecturer and Honorary Consultant in Rehabilitation Psychiatry, Royal Free and University College London Medical School and Camden and Islington NHS Foundation Trust: Richard Meier is Policy Analyst at the Royal College of Psychiatrists.

\section{References}

1 Killaspy $\mathrm{H}$, Harden C, Holloway F, King M. What do mental health rehabilitation services do and what are they for? A national survey in England. J Ment Health 2005; 14: 157-65.

2 Holloway F. The Forgotten Need for Rehabilitation in Contemporary Mental Health Services: A Position Statement from the Executive Committee of the Faculty of Rehabilitation and Social Psychiatry, Royal College of Psychiatrists. Royal College of Psychiatrists, 2005.

3 Mountain D, Killaspy $H$, Holloway F. Mental health rehabilitation services in the UK in 2007. Psychiatr Bull 2009; 33: 215-8.

4 Department of Health. National Service Framework for Mental Health. Department of Health, 1999.

5 Department of Health. Mental Health Policy Implementation Guide. Department of Health, 2001.

6 Glover G, Arts G, Babu KS. Crisis resolution/home treatment teams and psychiatric admission rates in England. Br J Psychiatry 2006; 189: 441-5.

7 Killaspy H, Bebbington PE, Blizard R, Johnson S, Nolan F, Pilling S, et al. The REACT study: a randomised evaluation of assertive community treatment in north London. BMJ 2006: 332: 815-20.

8 Craig T, Garety P, Power P, Rahaman N, Colbert S, Fornells-Ambrojo M et al. The Lambeth Early Onset (LEO) Team: randomised controlled trial of the effectiveness of specialised care for early psychosis. BMJ 2004; 329: 1067-71.

9 Killaspy H, Rambarran D, Bledin K. Mental health needs of clients of rehabilitation services: a survey in one trust. J Ment Health 2008; 17: 207-18.

10 Meltzer H. Treatment-resistant schizophrenia: the role of clozapine. Curr Med Res Opin 1997; 14: 1-20.

11 Green $M$. What are the functional consequences of neurocognitive deficits in schizophrenia? Am J Psychiatry 1996; 153: 321-30.

12 Wykes T, Dunn G. Cognitive deficit and the prediction of rehabilitation success in a chronic psychiatric group. Psychol Med 1992; 22: 389-98.

13 Social Exclusion Unit. Mental Health and Social Exclusion: Social Exclusion Unit Report. Office of the Deputy Prime Minister, 2004.

14 Harding CM, Brooks GW, Ashikaga T, Strauss JS, Breier A. The Vermont longitudinal study of persons with severe mental illness. I: Methodology, study sample, and overall status 32 years later. Am J Psychiatry 1987; 144: 718-26.

15 Trieman N, Leff J. Long-term outcome of long-stay psychiatric inpatients considered unsuitable to live in the community: TAPS Project 44. Br J Psychiatry 2002; 181: 428-32.

16 Ryan T, Pearsall A, Hatfield B, Poole R. Long term care for serious mental illness outside the NHS: a study of out of area placements. J Ment Health 2004: 13: 425-9.

17 Killaspy H, Rambarran D, Harden C, McClinton K, Caren G, Fearon D. A comparison of service users placed out of their local area and local rehabilitation service users. J Ment Health 2009; 18: 111-20.

18 Ryan T, Hatfield B, Sharma I, Simpson V, Mclntyre A. A census study of independent mental health sector usage across seven Strategic Health Authorities. J Ment Health 2007; 16: 243-53.

19 Mental Health Strategies. Out of Area Treatments 2004/5 - A Market out of Control? Mental Health Strategies, 2005.

20 Poole R, Ryan T, Pearsall A. The NHS, the private sector, and the virtual asylum. BMJ 2002; 325: 349-50.

21 Priebe S, Badesconyi A, Fioritti A, Hansson L, Kilian R, Torres-Gonzales F, et al. Reinstitutionalisation in mental health care: comparison of data on service provision from six European countries. BMJ 2005; 330: 123-6.

22 HM Government. New Horizons. A Shared Vision for Mental Health. TSO (The Stationery Office), 2009.

23 Roberts G, Wolfson P. The rediscovery of recovery: open to all. Adv Psychiatr Treat 2004; 10: 37-49.

24 Wolfson P, Holloway F, Killaspy H (eds). Enabling Recovery for People with Complex Mental Health Needs: A Template for Rehabilitation Services. Royal College of Psychiatrists, 2009. 